\title{
Cribriform-morular variant of papillary thyroid carcinoma: a distinctive type of thyroid cancer
}

\author{
Alfred King-yin Lam and Nassim Saremi \\ Cancer Molecular Pathology, School of Medicine and Menzies Health Institute Queensland, \\ Griffith University, Gold Coast, Australia
}

Correspondence should be addressed to A Lam

Email

a.lam@griffith.edu.au

\begin{abstract}
The aim of this systematic review is to study the features of cribriform-morular variant of papillary thyroid carcinoma (CMV-PTC) by analysing the 129 documented cases in the English literature. The disease occurred almost exclusively in women. The median age of presentation for CMV-PTC was 24 years. Slightly over half of the patients with CMV-PTC had familial adenomatous polyposis (FAP). CMV-PTC presented before the colonic manifestations in approximately half of the patients with FAP. Patients with FAP often have multifocal tumours in the thyroid. Microscopic examination of CMV-PTC revealed predominately cribriform and morular pattern of cancer cells with characteristic nuclear features of papillary thyroid carcinoma. Psammoma body is rare. On immunohistochemical studies, $\beta$-catenin is diffusely positive in CMV-PTC. The morular cells in CMV-PTC are strongly positive for CD10, bcl-2 and E-cadherin. Pre-operative diagnosis of CMV-PTC by fine-needle aspiration biopsy could be aided by cribriform architecture, epithelial morules and $\beta$-catenin immunostaining. Mutations of $A P C$ gene are found in the patients with CMV-PTC associated with FAP. In addition, mutations in CTNNB1, RETIPTC rearrangement and PI3K3CA mutations have been reported. BRAF mutation is negative in all CMV-PTC tested. Compared to conventional papillary thyroid carcinoma, CMV-PTC had a lower frequency of lymph node metastases at presentation (12\%) and distant metastases $(3 \%)$ as well as lower recurrence rates $(8.5 \%)$ and patients' mortality rates $(2 \%)$. To conclude, patients with CMV-PTC have distinctive clinical, pathological and molecular profiles when compared to conventional papillary thyroid carcinoma.
\end{abstract}

Endocrine-Related Cancer (2017) 24, R109-R121

\section{Introduction}

Cribriform-morular variant of papillary thyroid carcinoma (CMV-PTC) is an uncommon variant of papillary thyroid carcinoma. It is a variant of papillary thyroid carcinoma recognized in the current World Health Organization (WHO) classification of endocrine tumours (Lam 2017). However, when compared to other variants of papillary thyroid carcinoma, it was relatively recently characterized in the literature. The first well-illustrated case was reported by Chan and Loo from Hong Kong in 1990 (Chan \& Loo 1990). After this case, there were a few cases and a small series reported in the subsequent years (Yamashita et al. 1992, Harach et al. 1994, Hizawa et al. 1996, Mizukami et al. 1996, Perrier et al. 1998). Then, in 1999, Cameselle-Teijeiro and Chan coined the name of 
this type of cancer and identified the unique pathological features of this variant of papillary thyroid carcinoma (Cameselle-Teijeiro \& Chan 1999).

\section{Methods}

All the English literature that reported features of patients with CMV-PTC from PubMed database were analysed. Cases that had been presented in more than one study were counted only once to avoid duplication. Also, cases without demographic data were excluded. Overall, 129 CMV-PTC with well-documented characteristics were noted in the English literature (Chan \& Loo 1990, Yamashita et al. 1992, Harach et al. 1994, Hizawa et al. 1996, Mizukami et al. 1996, Perrier et al. 1998, CameselleTeijeiro \& Chan 1999, Iwama et al. 1999, Soravia et al. 1999, Chong et al. 2000, Cameselle-Teijeiro et al. 2001, 2009, Fenton et al. 2001, Kameyama \& Takami 2001, $\mathrm{Ng}$ et al. 2003, Rohaizak et al. 2003, Rosen et al. 2003, $\mathrm{Xu}$ et al. 2003, Chikkamuniyappa \& Jagirdar 2004, Kameyama etal. 2004, Kuma etal.2004, Tomoda etal.2004, Chuah et al. 2005, Dalal et al. 2006, Uchino et al. 2006, Subramaniam et al. 2007, Dong et al. 2009, Donnellan et al. 2009, Jung et al. 2009, Hirokawa et al. 2010, Baloch et al. 2011, Koo et al. 2011, Schaeffer et al. 2011, Crippa et al. 2012, Gronnier et al. 2012, Mogoş et al. 2012, Rossi et al. 2012, Boonyaarunnate et al. 2013, Chong et al. 2013, Nakazawa et al. 2013, Giannelli et al. 2014, Yeoh et al. 2014, Abdullah Suhaimi et al. 2015, Alikhan et al. 2015, Kwon et al. 2015, Liyanapathirana et al. 2015, Perea Del Pozo et al. 2015, Brehar et al. 2016, Casellas-Cabrera et al. 2016, Oh et al. 2016).

\section{Epidemiology}

The new edition of the World Health Organization (WHO) classification of endocrine tumours classified the papillary thyroid carcinoma into 15 variants (Lam 2017). Table 1 summarized the prevalence of the different variants of papillary thyroid carcinoma noted in surgical series.

CMV-PTC is one of the 15 variants and is very uncommon. In the English literature, only 3 larger populations of CMV-PTCs were reported. The first population was from Japan. This group of authors have reported CMV-PTC in different overlapping periods in a few publications. The largest series form this group was reported by Ito and coworkers in 2011 who had found 32 CMV-PTCs in the period 1991-2010 (Ito et al. 2011). However, no detailed information or prevalence of the disease was recorded in the publication. In 2015, authors
Table 1 Relative prevalence of different variants of papillary thyroid carcinoma in surgical biopsy series.

\begin{tabular}{lll}
\hline Variants of papillary thyroid carcinoma & & Relative prevalence \\
\cline { 1 - 2 } 1. Conventional/classical & & $40 \% *$ \\
2. Papillary microcarcinoma & & $25 \%$ \\
3. Encapsulated & $\sim 10 \% *$ \\
4. Follicular & $\sim 15 \% *$ \\
5. Diffuse sclerosing & $\sim 2 \%$ \\
6. Tall cell & $\sim 4 \%$ \\
7. Columnar cell & Rare, not known \\
8. Cribriform-morular & $\sim 0.2 \%$ \\
9. Hobnail & Rare, not known* \\
10. Papillary thyroid carcinoma with & Rare, not known \\
fibromatosis/fascitiis-like stroma & \\
11. Solid/trabecular & $1-3 \%$ \\
12. Oncocytic & Rare, not known* \\
13. Spindle cell & Not known \\
14. Clear cell & Rare, not known \\
15. Warthin like & Rare, not known* \\
\hline
\end{tabular}

*The proportion of these variants is estimated as the fourth edition of World Health Organization of endocrine tumours has updated the definitions of these variants.

from the same hospital reported a $0.3 \%$ (22 of 7228) prevalence of CMV-PTC in papillary thyroid carcinoma in the period 2005-2011 (Fujimoto et al. 2015). Also, in 2010, Hirokawa and coworkers from this hospital reported a prevalence of $0.22 \%$ (18 of 8583 ) of CMV-PTC in papillary thyroid carcinoma in the period 1991-2008 (Hirokawa et al. 2010). More recently, in 2004, Tomoda and coworkers presented 7 patients from the same hospital and noted a prevalence of $0.16 \%$ (7 of 4194) of CMV-PTV in papillary thyroid carcinoma in the period 1991-2003 (Tomoda et al. 2004). The other large population of CMV-PTCs were reported by Perrier and coworkers from Mayo Clinic and Cleveland Clinic in the USA who reported 11 cases of CMV-PTC (Perrier et al. 1998). However, the authors did not present the prevalence of CMV-PTC. The third large series of CMV-PTC was reported by Levy and coworkers in Memorial Sloan Kettering Cancer Centre in the USA in 2014 (Levy et al. 2014). The authors identified 11 patients with CMV-PTC of 6901 patients with papillary thyroid carcinoma in the period from 2001 to 2012. The prevalence of CMV-PTC was $0.16 \%$. Thus, CMV-PTC accounts for approximately $0.2 \%$ of all papillary thyroid carcinoma.

CMV-PTCs were more commonly reported in patients from either Japan $(n=47)$ or the USA $(n=27)$. Geographically, the reported cases in Asia comprised approximately $63 \%$ of the cases $(n=81)$. They were reported in Japan $(n=47)$, South Korea $(n=19)$, Singapore and Malaysia $(n=8)$, China (including Hong Kong $(n=6)$ and Sri Lanka $(n=1))$. It appears that CMV-PTC was more

Published by Bioscientifica Ltd 


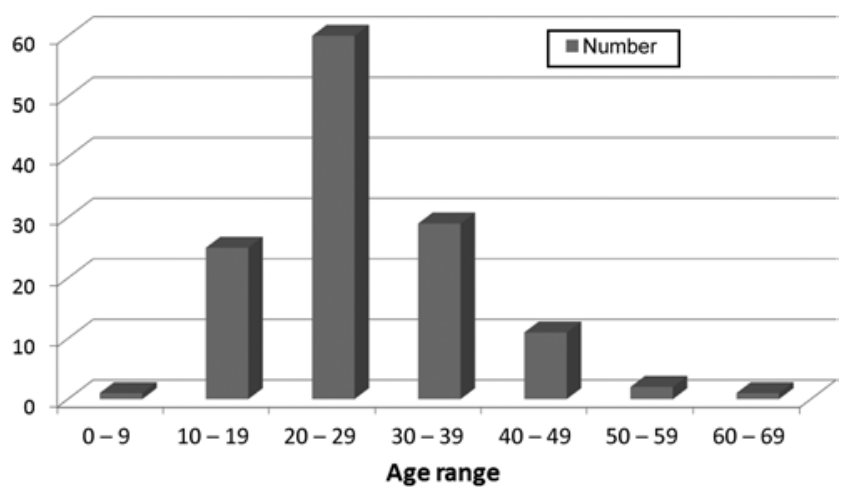

Figure 1

Bar chart showing the distribution of cases of CMV-PTC in different age groups, separated into decades of life.

common in Asian populations. The other cases were reported in America $(n=33 ; 26 \%)$ and Europe $(n=15 ; 11 \%)$.

Papillary thyroid carcinoma was often noted in adult in the fifth decade of life (mean age $=45$ years) (Lam et al. 2005). From the literature, CMV-PTC was most often seen in patients in the third decade of life (Fig. 1 and Table 2). The mean age and median age of patients with CMV-PTC were 28 and 24 , respectively. The age range of patients with CMV-PTC was from 8 to 69 years, and $89 \%(n=115)$ of the cancers were noted in patients aged younger than 40 years. It is worth noting that among the different variants of papillary thyroid carcinoma, diffuse sclerosing variant of papillary thyroid carcinoma also noted most often in patients at third decade of life (Pillai et al. 2015). Thus, both CMV-PTC and diffuse sclerosing variant of papillary thyroid carcinoma should be considered in thyroid cancer detected in young adults. From the accumulated data in the literature, CMV-PTC occurs in a slightly younger age than diffuse sclerosing variant of papillary thyroid carcinoma $(P=0.0001)$ (Pillai et al. 2015).

Table 2 Clinical and molecular differences between conventional papillary thyroid carcinoma and cribriformmorular variant of papillary thyroid carcinoma.

\begin{tabular}{|c|c|c|}
\hline Features & Conventional & Cribriform-morular \\
\hline Mean age & 45 & 28 \\
\hline Female to male ratio & $3: 1$ & $31: 1$ \\
\hline Mean diameter (mm) & 26 & 30 \\
\hline Association with FAP & Occasional & Noted in $53 \%$ \\
\hline $\begin{array}{l}\text { Lymph node metastases } \\
(\%)\end{array}$ & 43 & 12 \\
\hline Cancer recurrence $(\%)$ & 16 & 9 \\
\hline Mortality (\%) & 2.5 & 2 \\
\hline Braf mutation (\%) & $\sim 60$ & 0 \\
\hline Ras mutation & Uncommon & Uncommon \\
\hline $\begin{array}{l}\text { Non-Braf-non-Ras } \\
\text { mutation }\end{array}$ & Uncommon & $\begin{array}{l}\text { Common in the Wnt } \\
\text { signalling pathway }\end{array}$ \\
\hline
\end{tabular}
Printed in Great Britain
In patients with papillary thyroid carcinoma, the female-to-male ratio is 3 to 4:1 (Lam et al. 2005). On the other hand, CMV-PTC occurred almost exclusively in females. Of the 129 patients, $97 \%$ were females $(n=125)$ and $3 \%$ were males $(n=4)$. The female-to-male ratio was thus 31:1 (Table 2). The 4 male patients with CMVPTC were of ages 34, 40, 42 and 55, respectively (mean age $=43$ years). Male patients with CMV-PTC were found in similar age group as conventional papillary thyroid carcinoma. The difference of age at diagnosis of CMV-PTC between the genders was significant $(P=0.03)$.

\section{Clinical features}

Patients with CMV-PTC mostly present with a mass lesion in the neck discovered incidentally on palpation or on imaging. All the cases were euthyroid. Alikhan and coworkers had reported a case with ectopic production of serum human chorionic gonadotropin (Alikhan et al. 2015).

The most unique clinical feature of CMV-PTC is related to its relationship with familial adenomatous polyposis (FAP). FAP is an autosomal dominant polyposis syndrome characterized by hundreds of adenomas in the large intestine as well as in the upper gastrointestinal tract (Leoz et al. 2015, Waller et al. 2016). It is due to germline mutations in APC gene located on long (q) arm of chromosome 5 at position 22.2. The APC gene plays a role in Wnt signalling pathway. The APC protein functions as a tumour suppressor by negatively regulating the $\beta$-catenin oncoprotein. The individuals with FAP have almost $100 \%$ chance to develop colorectal cancer. The colorectal carcinoma in the setting of FAP could occur at young age and could be multiple. FAP accounted for $4 \%$ of patients with synchronous colorectal carcinoma (Lam et al. 2011, 2014).

There are 2 major types of FAP with extracolonic manifestations of FAP, namely Gardner syndrome and type 2 Turcot syndrome. Gardner syndrome is a subtype of FAP that has colonic lesions as well as lesions in many different organs (Gómez García \& Knoers 2009). The lesions are mostly benign such as epidermoid cyst, fibroma, desmoid tumour (fibromatosis), osteoma and congenital hypertrophy of the retinal pigment epithelium (CHRPE), etc. The pathogenesis of the lesions is postulated to be a ciliary dysfunction as both APC and the cilia have degradation of $\beta$-catenin as the common downstream target in the Wnt signalling pathway. Apart from colorectal cancer, patients with Gardner syndrome most often have small bowel cancer. The other cancers included pancreatic

Published by Bioscientifica Ltd 
cancer, hepatoblastoma, gastric cancer, bile duct cancer, adrenal cancer, central nervous system tumour as well as papillary thyroid carcinoma (Leoz et al. 2015).

Type 2 Turcot's syndrome is a very rare form of mutation of $A P C$ gene in which there is an association of intestinal polyposis and brain tumours - most often medulloblastoma (Gadish et al. 2005, Skomorowski et al. 2012). The occurrence of thyroid cancer in Turcot syndrome is extremely rare. In the literature, Crail reported a case of medulloblastoma, papillary thyroid carcinoma and colonic polyposis in 1949 (Crail 1949). The first and the only documented CMV-PTC and medulloblastoma was reported by Fenton and coworkers in 2001 (Fenton et al. 2001).

Devic and Bussy were first to recognize the association of colonic polyposis with thyroid mass in 1912 in French literature (Devic \& Bussy 1912). In 1949, Crail reported a case of papillary thyroid carcinoma in a patient with FAP, which was the first report of thyroid cancer in patient with FAP (Crail 1949). Then, Gardner in 1951 recognized thyroid cancer as extra-colonic manifestation in FAP (Gardner 1951). In 1968, Camiel and coworkers reported two sisters with FAP having papillary thyroid carcinoma (Camiel et al. 1968). Moreover, in 1994, Harach and coworkers first described that CMV-PTC is a unique variant of papillary thyroid carcinoma that could occur in the setting of FAP (Harach et al. 1994). In 1997, Bülow and Bülow in the United Kingdom have reported in a large cohort of patients with FAP that the incidence of thyroid carcinoma in FAP is 1.2\% (Bülow \& Bülow 1997).

From the data in literature, around half of the reported patients with CMV-PTC $(n=69 ; 53 \%)$ had FAP. In the 4 male patients with CMV-PTC, three had FAP. There was no difference in the age of presentation between patients with or without FAP. Of these patients with FAP, approximately half $(n=33 ; 48 \%)$ of the patients had the thyroid cancer as the first presentation. A few cases $(n=3)$ had the thyroid cancer detected 5 years before the presentation of the colonic lesions (polyposis or carcinoma) (Chong et al. 2000, Fenton et al. 2001, Jung et al. 2009). Jung and coworkers reported a patient with FAP having CMV-PTC detected 12 years before the presentation of the colonic lesions (Jung et al. 2009). On the other hand, the thyroid cancer could occur up to 38 years after the appearance of colonic lesions in FAP (Kameyama \& Takami 2001). The median lag time for the CMV-PTC was 10 years after the colonic lesions.

Of the CMV-PTC associated with FAP, other features of Gardner syndrome are sometimes noted. The most common lesion noted is desmoid tumour $(n=8)$ (Chong et al. 2000, Dalal et al. 2006, Crippa et al. 2012, Giannelli et al. 2014, Abdullah Suhaimi et al. 2015, Alikhan et al. 2015, Perea del Pozo et al. 2015). In addition, one patient presented with osteoma (Soravia et al. 1999).

\section{Macroscopic features}

Many of the CMV-PTCs were lobulated tan masses with encapsulation or circumscription. There is lack of gritty appearance of calcium. The mean maximum dimension of CMV-PTCs was $30 \mathrm{~mm}$ (range, 5-95 mm). The dimension of the CMV-PTC is similar to conventional papillary thyroid carcinoma in which the mean dimension is $26 \mathrm{~mm}$ (Lam et al. 2005). From the literature, there is no significant difference in size of CMV-PTC between patients with or without FAP.

The sites of the CMV-PTCs were mentioned in 81 cases documented in the literature. The distribution of the CMV-PTCs is different between patients with and without FAP $(P=0.0001)$. In patients without FAP, CMV-PTC often appears as solitary nodule with no site predilection. Only $16 \%$ (5 of 32) of the CMV-PTC without FAP involved both lobes of the thyroid. The remaining $84 \%$ (27 of 32 ) of CMV-PTC had roughly equal distribution in either lobe of the thyroid (13 in the left lobe and 14 in the right lobe). On the other hand, in patients with FAP, more than half of the patients ( 28 of $49 ; 57 \%$ ) had bilateral cancers with multinodular appearance. In the remaining patients with FAP having solitary lesion, it appeared that CMV-PTC was often located in the right lobe (15 in right lobe and 8 in left lobe).

\section{Microscopic features}

CMV-PTC had the characteristic nuclear features of papillary thyroid carcinoma (crowded, oval, optically clear, grooves and eosinophilic cytoplasmic pseudo inclusions and so forth) though the nuclei of them are not particular clear.

As the name of CMV-PTC implied, it is a papillary thyroid carcinoma with predominate cribriform and morular pattern of carcinoma cells. The cribriform pattern of CMV-PTC is represented by back-to-back follicles with anatomising bars and arches of cancer cells in the absence of intervening fibrovascular stroma (Fig. 2A). In some cases, the morular area may be difficult to be identified or non-existent. It is characterized by solid whorls of cells forming morules or nests with no keratinization or 

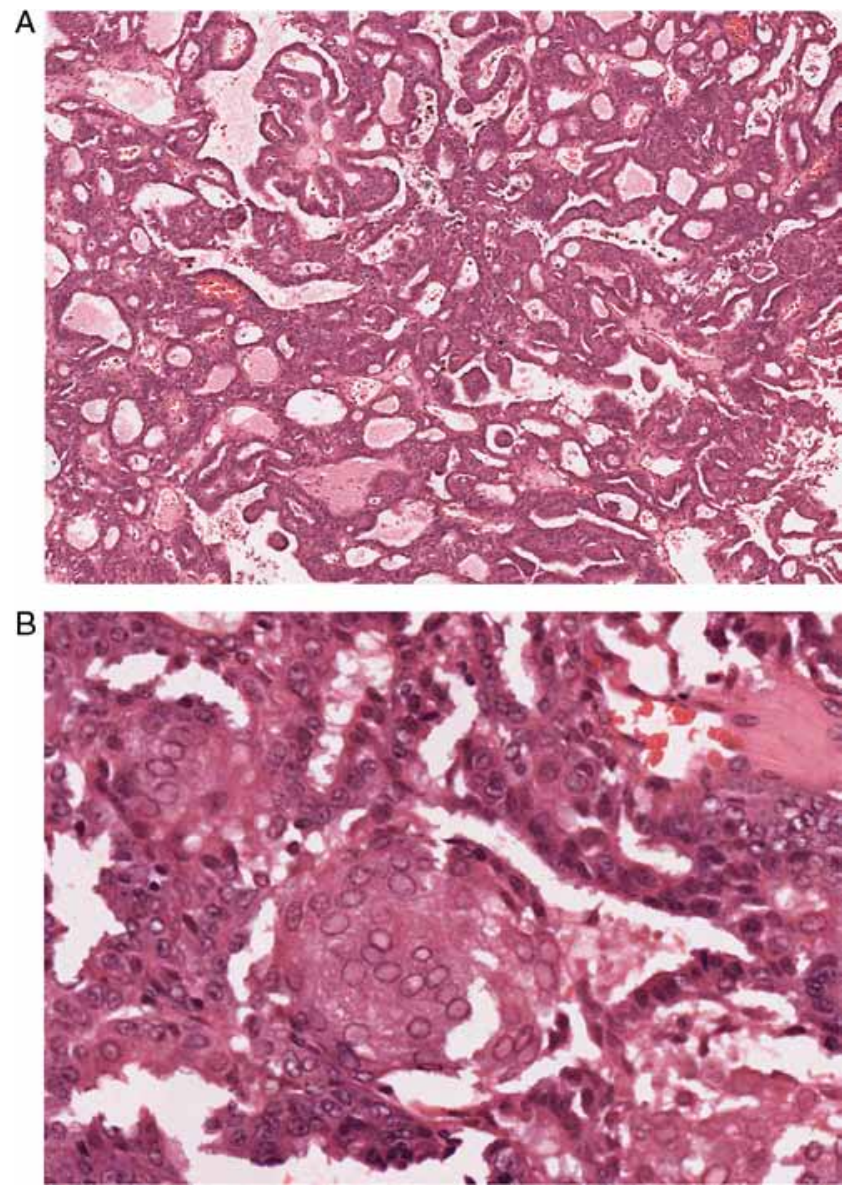

Figure 2

(A) CMV-PTC microscopic features: showing the characteristic cribriform pattern of arrangement of the tumour cells. This is composed of back-to-back follicles with anatomising bars and arches of cancer cells in the absence of intervening fibro vascular stroma (haematoxylin and eosin: $\times 8$ ). (B) CMV-PTC microscopic appearance: higher magnification showing the morular areas composed of tumour cells with indistinct border and clear nuclei (haematoxylin and eosin: $\times 25$ ).

intercellular bridges. Some nuclei within this area are clear and biotin rich (Fig. 2B). They can contribute to false immunostaining results.

On electron microscopic examination, the biotin-rich area pushes the nucleoli to the periphery of the nucleus and composed of randomly located fine microfilaments approximately $100 \mathrm{~nm}$ long (Yamashita et al. 1992, Kameyama et al. 2004). These clearings are not demarcated by a membrane. The morules do not contain remarkable cytoplasmic organelles.

Apart from the cribriform and morular morphology, aggressive histological features such as spindle cells in trabecular arrangements, tall and columnar cells with oxyphilic cytoplasm and frequent pseudo stratification as well as follicular pattern devoid of colloid could be present. Mitotic figures and necrosis are usually absent.
A case with hyaline globules as seen in adenoid cystic carcinoma was also described (Baloch et al. 2011).

In the setting of young patients with papillary thyroid carcinoma, the main clinical differential diagnosis of CMV-PTC is diffuse sclerosing variant of papillary thyroid carcinoma. Diffuse sclerosing variant of papillary carcinoma has prominent squamous areas, which could resemble morules. However, diffuse sclerosing variant had numerous psammoma bodies (Lam \& Lo 2006, Pillai et al. 2015). In contrast, in CMV-PTC, psammoma bodies are rare or absent. In the literature, psammoma bodies are seldom mentioned in the pathological descriptions. Of the 129 CMV-PTCs, 18 documented that no psammoma body was found. Only 4 cases had a few psammoma bodies present (Soravia et al. 1999, Jung et al. 2009, Mogoş et al. 2012).

Multifocal lesions are common in CMV-PTC. The prevalence of multifocal lesion was more often noted in cases with FAP. In the literature, 118 cases had the data of FAP status as well as presence of multifocal lesions documented. In patients with FAP, $72 \%$ (48 of 67) had multifocal cancers, whereas in patients without FAP, $24 \%$ (12 of 51$)$ had multifocal cancers $(P=0.0001)$. Overall, multiple tumour foci were noted in $51 \%$ of the CMV-PTCs.

CMV-PTC is often confined to the thyroid gland. In the literature in which the extent of the CMV-PTC was documented, extra-thyroid or large lesion (T3/4) cancers are noted in slightly more than one quarter $(28 \% ; 24$ of 87) of the cases. Also, capsular invasion and vascular invasion have been mentioned in a small portion of cases in 15 and 18 cases, respectively.

\section{Immunohistochemical features}

In CMV-PTC, the non-morular cancer cells had different staining properties when compared to the morular cancer cells (Dong et al. 2009, Jung et al. 2009). Both nonmorular and morular cells in CMV-PTC are positive for galectin 3 and p53 protein. The proliferative index (Ki-67) is higher in non-morular cancer cells and reported to be 1-5\% (Cameselle-Teijeiro \& Chan 1999).

The non-morular cancer cells are frequently positive for thyroid transcription factor-1 (TTF-1), vimentin, oestrogen receptor, progesterone receptor, cyclin D1, PTEN, epithelial membrane antigen (EMA) as well as lowand high-molecular-weight cytokeratins such as CK7, CK19 and 34ßE12 (Kwon et al. 2015). The staining for thyroglobulin, HBME- 1 and CK5/6 are variable and can be either focal or negative.

Published by Bioscientifica Ltd 
The morules of CMV-PTC are negative for thyroglobulin, TTF-1, oestrogen receptor, progesterone receptor and many types of cytokeratins. Cytokeratin 19 (CK19) is commonly strongly expressed in papillary thyroid carcinomas. It is also positive in the squamous metaplasia in diffuse sclerosing variant of papillary thyroid carcinoma (Pillai et al. 2015). In contrast, CK19 may express only weakly in the morules in CMV-PTC. Cytoplasmic staining of CD10 and nuclear staining of bcl-2 are strongly positive in the morular cells but weak or not positive in the non-morular area (Giannelli et al. 2014).

$\beta$-Catenin and E-cadherin play a crucial role in cellto-cell adhesion and maintaining epithelial morphology (Chow et al. 2001, Si et al. 2001, Chang et al. 2002). This cadherin/catenin complex also regulates cell motility and is believed to function as an invasion suppressor system (Rocha et al. 2001). $\beta$-Catenin is diffusely positive in both cytoplasm and nucleus of both types of cancer cells in CMV-PTC, whereas normal epithelium of thyroid gland shows membranous staining pattern. The strong expression of $\beta$-catenin is a hallmark staining in CMVPTC in both FAP-associated or non-associated cases.

Loss of expression of E-cadherin, a cellular adhesion molecule, contributes to cancer metastases. Accordingly, studies have showed pronounced reduction of E-cadherin protein expression in the cell membrane, which was accompanied by the relocation of the protein staining to the cytoplasm in cancer (Rocha et al. 2001). Conventional papillary thyroid carcinoma showed heterogeneous loss of E-cadherin expression. In contrast, in CMV-PTC, E-cadherin was strongly and diffusely membranous positive in morular cells, whereas it was focally positive in non-morular cancer cells. Morular cells may decrease the metastatic or invasiveness of CMV-PTC. They may contribute to the relative lower biological or clinical aggressive of CMV-PTC when compared to other variants of papillary thyroid carcinoma.

\section{Pre-operative investigations}

There are two series in the literature focusing on the ultrasonic features of CMV-PTC. Chong and coworkers in 2013 reported that the majority of the thyroid nodules in 5 patients with CMV-PTC were well defined, had oval to round shapes and were hypoechoic and solid without calcification (Chong et al. 2013). Also, Fujimoto and coworkers in 2015 from a study of 22 patients with CMV-PTC noted that CMV-PTC had smooth or focal jagged margin, hypoechoic nodule, lateral shadow, posterior acoustic enhancement, poor marginal and internal vascularity and absence of micro-calcification (Fujimoto et al. 2015). These ultrasonic findings of CMVPTC resembled those of follicular tumour or nodular hyperplasia of thyroid instead of papillary thyroid carcinoma. Therefore, CMV-PTC did not reveal the features of malignancy in ultrasonic examination. These benign ultrasonic features make pre-operative diagnosis of CMV-PTC difficult.

In the literature, $63 \%$ (81 of the 129) of the patients with CMV-PTC had fine-needle aspiration performed before operation. Of these, 95\% (77 of 81) of the aspirates showed features either diagnostic or suspicious of thyroid carcinoma.

In 1996, Hizawa and coworkers from Japan first reported that fine-needle aspiration was done before operation of the CMV-PTC. The diagnosis on fineneedle aspiration was consistent with thyroid cancer (Hizawa et al. 1996). No detail of the cytological feature was given in the report. In 2010, Koo and coworkers from South Korea described the cytological features of five CMV-PTCs as well as reviewing 10 cases from the previous studies (Koo et al. 2011). The authors described that cytological features specific for CMV-PTC included cribriform architecture, epithelial morules and columnar cells. In addition, the $\beta$-catenin immunocytochemistry (nuclear and cytoplasmic positivity) could be used to help to diagnose CMV-PTC on cell block (Koo et al. 2011). Also in 2010, Hirokawa and coworkers in Japan documented 10 cytological features in 18 CMV-PTCs (Hirokawa et al. 2010). In addition to the cribriform architecture, epithelial morules and papillary arrangement of columnar cells, 7 other features were described in the cytological smears including spindle cells, peculiar nuclear clearing (palestaining area occupying most of the nuclei, usually with condensed chromatin in the periphery of the membrane and positive for biotin), obscure ground-glass nuclei, hyper cellularity, foamy or hemosiderin-laden histiocytes, hyaline materials as well as the absence of colloid in the background. It is worth noting that psammoma body and multi-nucleated giant cells characteristics of papillary thyroid carcinoma were not seen in all the cytological cases in the series. In the case series of Koo and coworkers, one had psammoma body reported in the smear (Koo et al. 2011). Thus, in the appropriate settings such as the presence of characteristic cytological features, relative young patients' age, clinical suspicious or confirmation of FAP as well as the presence of material for $\beta$-catenin 
immunocytochemistry (nuclear and cytoplasmic positivity), the diagnosis of CMV-PTC could be made by fine-needle aspiration biopsy before operation.

\section{Molecular pathogenesis}

The works of the Cancer Genome Atlas (TCGA) research network have revolutionized our understanding of molecular pathogenesis of thyroid carcinoma (Cancer Genome Atlas Research Network 2014, Yoo et al. 2016). The findings also resulted in a new classification of thyroid tumours that is incorporated in the fourth edition of the WHO classification of endocrine tumours (Lam 2017). In brief, large majority of papillary thyroid carcinomas are driven by mutations in either $B R A F$ (specifically $B R A F V 600 E)$ or $R A S$, both of which deregulate the mitogen-activated protein kinase (MAPK) signalling pathway. $B R A F V 600 E$-like tumours have conventional papillary morphology (conventional or tall cell variant of papillary thyroid carcinoma), whereas RAS-like tumours have follicular growth pattern and are encapsulated in greater than $80 \%$ of cases (Giordano 2016). A portion of the RASlike tumours was now classified as non-invasive follicular thyroid neoplasm with papillary-like features (NIFTP) (Lam 2017). These groups of papillary thyroid carcinoma have distinctive clinical accounted for approximately $75 \%$ of papillary thyroid carcinoma. Other than BRAFV6OOElike tumours and $R A S$-like tumours, the other papillary thyroid carcinomas are labelled as non-BRAF-non- $R A S$ tumours. They were seen with other genetic alterations such as EIF1AX (eukaryotic translation initiation factor $1 A$ and X-linked), PPM1D (protein phosphatase and $\mathrm{Mg} 2+/ \mathrm{Mn} 2+-$ dependent 1D) and CHEK2 (checkpoint kinase 2) (Cancer Genome Atlas Research Network 2014).

Ninety-eight percent of 402 papillary thyroid carcinomas in TCGA are conventional papillary thyroid carcinoma, follicular variant of papillary thyroid carcinoma and tall cell variant papillary thyroid carcinoma (Cancer Genome Atlas Research Network 2014). Two cases of CMV-PTC were examined in TCGA. They were of pathological stages - T3N1. One is from a 19-year-old female with a $B R A F$-like score whereas the other is from a 28-year-old man with fusion of RET and a RAS-like score. Thus, the molecular data of CMV-PTC from the TCGA are limited. The molecular pathogenesis of CMV-PTC summarized from the literature in the following sections. CMV-PTC likely belongs to non-BRAF-non-RAS group of papillary thyroid carcinoma on molecular classification.

\section{MAPK and PI3K/Act pathways and TERT}

The mitogen-activated protein kinase (MAPK) and PI3K (phosphoinositide 3-kinase)/Akt (protein kinase B) pathways are major pathways for pathogenesis of follicular-derived thyroid carcinoma (Rahman et al. 2015). Interactions of these two pathways were demonstrated in follicularderived thyroid carcinoma (Rahman et al. 2016). In addition, TERT (telomerase reverse transcriptase) is also commonly studied in papillary thyroid carcinoma as a prognostic indicator (Vinagre et al. 2013, Melo et al. 2014).

P13K/Akt pathway is activated by either the loss of PTEN expression or a PIK3CA mutation, resulting in downstream $\beta$-catenin activation. In the literature, only Kwon and coworkers in 2015 have reported three CMVPTCs with PIK3CA mutation (Kwon et al. 2015). However, the mutation was not detected in a case tested by Oh and coworkers (Oh et al. 2016).

$M A P K$ pathway is more commonly studied in cancer and $B R A F, R A S$ and $R E T / P T C$ are common activators in the pathway. K-RAS mutation has been reported once in an 18-year-old woman with FAP and CMV-PTC by Giannelli and coworkers (Giannelli et al. 2014). On the other hand, the other 7 cases tested in the literature were negative for RAS mutations (Rossi et al. 2012, Nakazawa et al. 2013, Kwon et al. 2015, Brehar et al. 2016, Oh et al. 2016). It appears that RAS mutation is uncommon in CMV-PTC.

$B R A F$ mutation was noted in approximately $45 \%$ of papillary thyroid carcinoma (Pakneshan et al. 2013). It was often noted in conventional papillary thyroid carcinoma of advanced pathological stages as well as those associated with lymphocytic thyroiditis (Smith et al. 2011). Multinational studies have demonstrated that $B R A F$ mutation in papillary thyroid carcinoma is associated with increased mortality and cancer recurrent rate (Xing et al. 2013, 2015). In the literature, BRAF mutation was tested in 18 cases of CMV-PTC (Rossi et al. 2012, Nakazawa et al. 2013, Giannelli et al. 2014, Kwon et al. 2015, Brehar et al. 2016, Oh et al. 2016), and the results showed that these cancers were negative for $B R A F$ mutation. The absence of $B R A F$ mutation in CMV-PTC may explain the relative indolent nature of this type of papillary thyroid carcinoma.

Rearrangement of the RET oncogene (also known as $R E T / P T C$ rearrangement) is an important genetic alteration that has been reported in earlier years. It is an early molecular event identified in papillary thyroid carcinomas (Lam et al. 1998). RET/PTC rearrangement is more commonly found in thyroid carcinomas in children and young adults as well as in papillary thyroid carcinomas 
associated with radiation exposure (Klugbauer et al. 1995, Nikiforov 2002). In CMV-PTC, 4 of the 6 cases (67\%) tested in 4 different studies showed RET/PTC rearrangement (Soravia et al. 1999, Rossi et al. 2012, Giannelli et al. 2014, Brehar et al. 2016). Thus, RET/PTC rearrangement appears to be involved in the pathogenesis of a portion of papillary thyroid carcinomas in young patients. These papillary thyroid carcinomas include diffuse sclerosing variant of papillary thyroid carcinoma and CMV-PTC (Pillai et al. 2015).

Telomerase activation has been detected in papillary thyroid carcinoma (Lo et al. 1999). TERT (telomerase reverse transcriptase) is a catalytic subunit of telomerase that maintains telomere repeats in DNA strands. TERT promoter mutations have been observed in thyroid carcinomas with aggressive biological behaviours. It is associated with tumour size, advanced stage, extrathyroidal invasion, lymph node metastases, distant metastases, BRAF mutation positivity, cancer recurrence and poor prognosis of patients with papillary thyroid carcinoma (Vinagre et al. 2013, Melo et al. 2014). Oh and coworkers in 2016 have reported the mutation in a 45-year-old woman with CMV-PTC (Oh et al. 2016). The case also had aggressive clinical course with lymph nodes and bone metastases.

\section{Wnt signalling pathway}

Wnt signalling pathway is important in carcinogenesis, tissue regeneration and embryonic development (Reguart et al. 2005). APC and $\beta$-catenin are the key members of the pathway. The mutations of either of these genes will elevate levels of $\beta$-catenin in the nucleus and cytoplasm. Nuclear and cytoplasmic $\beta$-catenin protein expression is a feature of CMV-PTC.

In patients with FAP, germline mutations of $A P C$ occurring before codon 1220 have a strong correlation with the development of thyroid cancer (Cetta et al. 2000). In CMV-PTC, germline mutations, somatic mutations and loss of heterozygosity of $A P C$ are frequently observed. In the literature, 18 of 28 (64\%) of CMV-PTC tested positive for aberrations in APC gene. Both somatic and germline mutations of APC were reported in CMV-PTC (Iwama et al. 1999, Uchino et al. 2006).

The accumulation of $\beta$-catenin could be caused by mutation of the $\beta$-catenin gene, CTNNB1. The mutation was first reported by $\mathrm{Xu}$ and coworkers in $5 \mathrm{CMV}$ PTCs (Xu et al. 2003). Mutation of CTNNB1 was also reported in one of the CMV-PTCs by Jung and coworkers
(Jung et al. 2009). In the literature, 32\% (6 of the 19) of CMV-PTC was positive for mutation of CTNNB1 (Xu et al. 2003, Uchino et al. 2006, Cameselle-Teijeiro et al. 2009, Dong et al. 2009, Jung et al. 2009, Nakazawa et al. 2013, Kwon et al. 2015). The mutation could occur in CMV-PTC not associated with FAP, indicating that the mutation could play a role in non-FAP-associated CMV-PTC. As $\beta$-catenin accumulation is critical in the epithelial budding, branching and follicular formation in embryogenesis, Dalal and coworkers proposed that the cribriform pattern of CMV-PTC resembles the epithelial budding in embryos and the morules look like the hair formation noted in embryogenesis (Dalal et al. 2006).

In cases where $A P C$ and CTNNB1 are not found, aberrant upstream events in Wnt signalling may be related to aberrant nuclear localization of $\beta$-catenin noted in immunohistochemistry as well as the carcinogenesis of CMV-PTC.

\section{Metastases}

In contrast to conventional papillary thyroid carcinomas or diffuse sclerosing variant of papillary thyroid carcinoma, CMV-PTC had low prevalence of lymph node metastases (Table 2). In large series, lymph node metastases were noted in $43 \%$ of patients with conventional papillary thyroid carcinoma and in $80 \%$ of patients with diffusing sclerosing variant of papillary thyroid carcinoma (Lam et al. 2005, Pillai et al. 2015). In CMV-PTC, 12\% (14 of 120) of patients had lymph nodes metastases at the time of surgery.

Distant metastases were uncommon in patients having CMV-PTC. In the literature, only 4 patients with CMV-PTC had distant metastases, accounting for 3\% of the reported CMV-PTC in the literature. The first case was documented by Fenton and coworkers in 2001. The authors reported a CMV-PTC with cancer recurrence and bone metastases in a 50-year-old woman 30 years after the resection of primary thyroid cancer (Fenton et al. 2001). Also, Cameselle-Teijeiro and coworkers presented a 42-year-old man with known FAP having a CMV-PTC associated with neuroendocrine carcinoma component. The patient died with lung and brain metastases (Cameselle-Teijeiro et al. 2009). In addition, Nakazawa and coworkers reported a 35-year-old woman having CMV-PTC with a component of poorly differentiated thyroid carcinoma having bone and lung metastases (Nakazawa et al. 2013). Furthermore, in 2016, Oh and coworkers presented a 45-year-old woman with CMV-PTC 
showing TERT (telomerase reverse transcriptase) promoter mutation and having bone metastases (Oh et al. 2016). Overall, CMV-PTCs with distant metastases were seen in patients of age older than mean age of the patients with CMV-PTC. It is worth noting that three of these four patients with distant metastases had either unusual histological or molecular features.

\section{Prognosis}

In the literature, $8.5 \%(n=11$ of 129$)$ of patients with CMV-PTC showed recurrence of cancer (Table 2). For reference, the recurrence rate of diffuse sclerosing variant of papillary thyroid carcinoma was $14 \%$ (Pillai et al. 2015). In multi-national study, the recurrence rate in conventional papillary thyroid carcinoma was $16.1 \%$ (Xing et al. 2015). The recurrence rate in aggressive variant of papillary thyroid carcinoma, tall cell variant, was $27.3 \%$ whereas that of follicular variant of papillary thyroid carcinoma was $9.1 \%$. Thus, the overall recurrence rate of CMV-PTC was low and similar to that of follicular variant of papillary thyroid carcinoma.

Three deaths were reported from the patients with CMV-PTC. Perrier and coworkers in 1998 recorded a 29-year-old female patient with CMV-PTC who had cancer recurrence at 6 months and died at 85 months after the operation (Perrier et al. 1998). In this study having 11 cases of CMV-PTC, the 5-year and 20-year survivals of the patients with CMV-PTC were 90\% and 77\%, respectively. Also, Fenton and coworkers in 2001 reported a 20-yearold woman with recurrence having distant metastases died 30 years after the resection of primary thyroid cancer (Fenton et al. 2001). In addition, Cameselle-Teijeiro and coworkers in 2009 presented a case in a 42-year-old man with known FAP having a neuroendocrine carcinoma component and died with lung and brain metastases 17 months after diagnosis (Cameselle-Teijeiro et al. 2009). Thus, patients with CMV-PTC have low mortality rate. On the other hand, cancer-related death could occur after a long lag time after the primary operation.

Disease-related mortality is uncommon and was noted in $2 \%(n=3 / 129)$ of the patients with CMV-PTC (Table 2$)$. In multi-national study, disease-related mortality in conventional papillary thyroid carcinoma was found to be $2.5 \%$ (Xing et al. 2015). On the other hand, the disease-related mortality in aggressive variant of papillary thyroid carcinoma, tall cell variant, was $6.7 \%$ whereas that of follicular variant of papillary thyroid carcinoma was $0.6 \%$. Also, the disease-related mortality in diffuse sclerosing variant of papillary thyroid carcinoma was 3\% (Pillai et al. 2015). Thus, the prognosis of the CMV-PTC is similar to that of conventional thyroid carcinoma.

\section{Clinical management}

As the prognosis of CMV-PTC is similar to conventional papillary thyroid carcinoma, standard approach for the management of conventional papillary thyroid carcinoma based on the clinical and pathological risk factors should be appropriate (Pacini \& Castagna 2012, Raue \& Frank-Raue 2016). Total thyroidectomy is sufficient for the treatment of most cancers. Lymph node dissection could be performed when necessary. The patients may have radioiodine therapy to detect and destroy any metastases and residual disease in thyroid. External beam radiotherapy may be used as adjuvant therapy in patients having locally invasive disease and in the older patients. In addition, CMV-PTC could be related to FAP and occur before the other manifestations of other diseases associated with FAP. Therefore, the management of the patients with CMV-PTC should also focus on the detection of other pathologies related to FAP as well as awareness of genetic implications of FAP in other family members.

\section{Conclusion}

CMV-PTC is characterized by unique clinical features (younger age at presentation, almost exclusively in women as well as the association with FAP). It has specific microscopic features (predominate cribriform and morular pattern of carcinoma cells with biotin-rich nuclei, multifocality and lack of psammoma bodies) as well as immunohistochemical pattern (positive to betacatenin). In addition, CMV-PTC has distinctive molecular pathogenesis through the Wnt signalling pathway. These characteristics of CMV-PTC cast doubts on labelling the cancer as a variant of papillary thyroid carcinoma. Nevertheless, CMV-PTC had nuclear characteristic of papillary thyroid carcinoma and Wnt signalling pathway alternations are noted in some conventional papillary thyroid carcinomas. Thus, CMV-PTC is grouped as an uncommon and a very unique variant of papillary thyroid carcinoma.

Patients with CMV-PTC have low incidence of lymph node metastases and cancer recurrence. Despite this, late recurrence could occur, and long-term follow up is required for this group of patients. In the settings of FAP,

Published by Bioscientifica Ltd. 
family screening and detection for other manifestations are important in the management of the patients. It is important to recognize this unique variant of papillary thyroid carcinoma as it occurs in specific clinical context and has unique pathological, immunohistochemical and molecular features.

\section{Declaration of interest}

The authors declare that there is no conflict of interest that could be perceived as prejudicing the impartiality of this review.

\section{Funding}

This work did not receive any specific grant from any funding agency in the public, commercial, or not-for-profit sector.

\section{References}

Abdullah Suhaimi SN, Nazri N, Nani Harlina ML, Md Isa N \& Muhammad R 2015 Familial adenomatous polyposis-associated papillary thyroid cancer. Malaysian Journal of Medical Sciences 22 69-72. (available at: https://www.ncbi.nlm.nih.gov/pmc/articles/ PMC4683851/)

Alikhan M, Koshy A, Hyjek E, Stenson K, Cohen RN \& Yeo KT 2015 Discrepant serum and urine $\beta$-hCG results due to production of $\beta$ hCG by a cribriform-morular variant of thyroid papillary carcinoma. Clinica Chimica Acta 438 181-185. (doi:10.1016/j. cca.2014.08.026)

Baloch ZW, Segal JP \& Livolsi VA 2011 Unique growth pattern in papillary carcinoma of the thyroid gland mimicking adenoid cystic carcinoma. Endocrine Pathology 22 200-205. (doi:10.1007/s12022011-9174-7)

Boonyaarunnate T, Olson MT, Bishop JA, Yang GC \& Ali SZ 2013 Cribriform morular variant of papillary thyroid carcinoma: clinical and cytomorphological features on fine-needle aspiration. Acta Cytologica 57 127-133. (doi:10.1159/000345879)

Brehar AC, Terzea DC, Ioachim DL, Procopiuc C, Brehar FM, Bulgăr AC, Ghemigian MV \& Dumitrache C 2016 Cribriform-morular variant of papillary thyroid carcinoma at pediatric age - case report and review of the literature. Romanian Journal of Morphology and Embryology $5 \mathbf{7}$ 531-537. (available at: http://www.rjme.ro/RJME/resources/ files/570216531537.pdf)

Bülow C \& Bülow S 1997 Is screening for thyroid carcinoma indicated in familial adenomatous polyposis? The Leeds Castle Polyposis Group. International Journal of Colorectal Disease 12 240-242. (doi:10.1007/s003840050097)

Cameselle-Teijeiro J \& Chan JK 1999 Cribriform-morular variant of papillary carcinoma: a distinctive variant representing the sporadic counterpart of familial adenomatous polyposis-associated thyroid carcinoma? Modern Pathology 12 400-411.

Cameselle-Teijeiro J, Ruiz-Ponte C, Loidi L, Suarez-Peñaranda J, Baltar J \& Sobrinho-Simoes M 2001 Somatic but not germline mutation of the APC gene in a case of cribriform-morular variant of papillary thyroid carcinoma. American Journal of Clinical Pathology 115 486-493. (doi:10.1309/T9CC-JNMD-1WGP-YPAF)

Cameselle-Teijeiro J, Menasce LP, Yap BK, Colaco RJ, Castro P, Celestino R, Ruíz Ponte C, Soares P \& Sobrinho-Simões M 2009 Cribriform-morular variant of papillary thyroid carcinoma: molecular characterization of a case with neuroendocrine differentiation and aggressive behavior. American Journal of Clinical Pathology 131 134-142. (doi:10.1309/AJCP7ULSOVSISBEB)

Camiel MR, Mulé JE, Alexander LL \& Benninghoff DL 1968 Association of thyroid carcinoma with Gardner's syndrome in siblings. New England Journal of Medicine 278 1056-1058. (doi:10.1056/ NEJM196805092781908)

Cancer Genome Atlas Research Network 2014 Integrated genomic characterization of papillary thyroid carcinoma. Cell 59 676-690. (doi:10.1016/j.cell.2014.09.050)

Casellas-Cabrera N, Díaz-Algorri Y, Carlo-Chévere VJ, González-Pons M, Rodríguez-Mañón N, Pérez-Mayoral J, Bertrán-Rodríguez C, SotoSalgado M, Giardiello FM, Rodríguez-Quilichini S, et al. 2016 Risk of thyroid cancer among Caribbean Hispanic patients with familial adenomatous polyposis. Familial Cancer 15 267-274. (doi:10.1007/ s10689-015-9862-4)

Cetta F, Montalto G, Gori M, Curia MC, Cama A \& Olschwang S 2000 Germline mutations of the APC gene in patients with familial adenomatous polyposis-associated thyroid carcinoma: results from a European cooperative study. Journal of Clinical Endocrinology and Metabolism 85 286-292. (doi:10.1210/ jc.85.1.286)

Chan JK \& Loo KT 1990 Cribriform variant of papillary thyroid carcinoma. Archives of Pathology and Laboratory Medicine $\mathbf{1 1 4}$ 622-624.

Chang HW, Chow V, Lam KY, Wei WI \& Yuen A 2002 Loss of E-cadherin expression resulting from promoter hypermethylation in oral tongue carcinoma and its prognostic significance. Cancer 94 386-392. (doi:10.1002/cncr.10211)

Chikkamuniyappa S \& Jagirdar J 2004 Cribriform-morular variant of papillary carcinoma: association with familial adenomatous polyposis - report of three cases and review of literature. International Journal of Medical Science 1 43-49. (doi:10.7150/ ijms.1.43)

Chong J, Koshiishi N, Kurihara K, Kubono S, Kawai T \& Fukayama M 2000 Aspiration and imprint cytopathology of thyroid carcinoma associated with familial adenomatous polyposis. Diagnostic Cytopathology 23 101-115. (doi:10.1002/10970339(200008) 23:2<101::AID-DC7>3.0.CO;2-0)

Chong Y, Shin JH, Oh YL, Han BK \& Ko EY 2013 Cribriform-morular variant of papillary thyroid carcinoma: ultrasonographic and clinical characteristics. Thyroid 23 45-49. (doi:10.1089/ thy.2011.0534)

Chow V, Yuen APW, Lam KY, Tsao GSW, Ho WK \& Wei WI 2001 A comparative study of the clinicopathological significance of E-cadherin and catenins $(\alpha, \beta, \gamma)$ expression in the surgical management of oral tongue carcinoma. Journal of Cancer Research and Clinical Oncology 127 59-63. (doi:10.1007/s004320000177)

Chuah KL, Hwang JS, Ng SB, Tan PH, Poh WT \& Au VS 2005 Cytologic features of cribriform-morular variant of papillary carcinoma of the thyroid: a case report. Acta Cytologica 49 75-80. (doi:10.1159/ 000326100)

Crail HW 1949 Multiple primary malignancies arising in the rectum, brain, and thyroid; report of a case. United States Naval Medical Bulletin 49 123-128.

Crippa S, Saletti P, Barizzi J \& Mazzucchelli L 2012 The clinical management in familial adenomatous polyposis deserves continuous monitoring for thyroid carcinoma. BMJ Case Reports 2012 bcr2012007046. (doi:10.1136/bcr-2012-007046)

Dalal KM, Moraitis D, Iwamoto C, Shaha AR, Patel SG \& Ghossein RA 2006 Clinical curiosity: cribriform-morular variant of papillary thyroid carcinoma. Head and Neck 28 471-476. (doi:10.1002/ hed.20383)

Devic C \& Busy J 1912 Un cas de polypose adenomateuse generalisee a tout I'intestin. Archives Francaises Des Maladies De L'Appareil Digestif 6 278-289. http://erc.endocrinology-journals.org

DOI: 10.1530/ERC-17-0014
(C) 2017 Society for Endocrinology Printed in Great Britain
Published by Bioscientifica Ltd 
Dong Y, Zhou X, Yin H, Wang J, Zhou H \& Lu G 2009 Cribriformmorular variant of papillary thyroid carcinoma: report of three cases and review of the literature. Pathology 41 509-512. (doi:10.1080/00313020903041101)

Donnellan KA, Bigler SA \& Wein RO 2009 Papillary thyroid carcinoma and familial adenomatous polyposis of the colon. American Journal of Otolaryngology 30 58-60. (doi:10.1016/j. amjoto.2008.01.001)

Fenton PA, Clarke SE, Owen W, Hibbert J \& Hodgson SV 2001 Cribriform variant papillary thyroid cancer: a characteristic of familial adenomatous polyposis. Thyroid 11 193-197. (doi:10.1089/1 05072501300042965)

Fujimoto T, Hirokawa M, Ota H, Yabuta T, Fukushima M, Kobayashi K, Amino N \& Miyauchi A 2015 Characteristic sonographic features of cribriform papillary thyroid carcinoma for differentiation from other thyroid nodules. Journal of Medical Ultrasound 42 83-87. (doi:10.1007/s10396-014-0555-7)

Gadish T, Tulchinsky H, Deutsch AA \& Rabau M 2005 Pinealoblastoma in a patient with familial adenomatous polyposis: variant of Turcot syndrome type 2 ? Report of a case and review of the literature. Diseases of Colon and Rectum 48 2343-2346. (doi:10.1007/s10350005-0201-y)

Gardner EJ 1951 A genetic and clinical study of intestinal polyposis, a predisposing factor for carcinoma of the colon and rectum. American Journal of Human Genetics 3 167-176. (available at: https://www.ncbi. nlm.nih.gov/pmc/articles/PMC1716321/)

Giannelli SM, McPhaul L, Nakamoto J \& Gianoukakis AG 2014 Familial adenomatous polyposis-associated, cribriform morular variant of papillary thyroid carcinoma harboring a K-RAS mutation: case presentation and review of molecular mechanisms. Thyroid $\mathbf{2 4}$ 1184-1189. (doi:10.1089/thy.2013.0589)

Giordano TJ 2016 Follicular cell thyroid neoplasia: insights from genomics and the Cancer Genome Atlas research network. Current Opinion in Oncology 28 1-4. (doi:10.1097/CCO.0000000000000248)

Gómez García EB \& Knoers NV 2009 Gardner's syndrome (familial adenomatous polyposis): a cilia-related disorder. Lancet Oncology 10 727-735. (doi:10.1016/s1470-2045(09)70167-6)

Gronnier C, Donatini G, Leteurtre E, Do Cao C \& Carnaille B 2012 Cribriform-morular variant of papillary thyroid carcinoma: characteristic histologic feature of adenomatous polyposis: a case report. Annales D'endocrinologie 73 213-215. (doi:10.1016/j. ando.2012.01.003)

Harach HR, Williams GT \& Williams ED 1994 Familial adenomatous polyposis associated thyroid carcinoma: a distinct type of follicular cell neoplasm. Histopathology 25 549-561. (doi:10.1111/ j.1365-2559.1994.tb01374.x)

Hirokawa M, Maekawa M, Kuma S \& Miyauchi A 2010 Cribriformmorular variant of papillary thyroid carcinoma - cytological and immunocytochemical findings of 18 cases. Diagnostic Cytopathology 38 890-896. (doi:10.1002/dc.21309)

Hizawa K, Iida M, Yao T, Aoyagi K, Oohata Y, Mibu R, Yamasaki K, Hirata T \& Fujishima M 1996 Association between thyroid cancer of cribriform variant and familial adenomatous polyposis. Journal of Clinical Pathology 49 611-613. (doi:10.1136/jcp.49.7.611)

Ito Y, Miyauchi A, Ishikawa H, Hirokawa M, Kudo T, Tomoda C \& Miya A 2011 Our experience of treatment of cribriform morular variant of papillary thyroid carcinoma; difference in clinicopathological features of FAP-associated and sporadic patients. Endocrine Journal 58 685-689. (doi:10.1507/endocrj. EJ11-0022)

Iwama T, Konishi M, Iijima T, Yoshinaga $\mathrm{K}$, Tominaga T, Koike M \& Miyaki M 1999 Somatic mutation of the APC gene in thyroid carcinoma associated with familial adenomatous polyposis. Japanese Journal of Cancer Research 90 372-376. (doi:10.1111/ j.1349-7006.1999.tb00757.x
Jung CK, Choi YJ, Lee KY, Bae JS, Kim HJ, Yoon SK, Son YI, Chung JH \& Oh YL 2009 The cytological, clinical, and pathological features of the cribriform-morular variant of papillary thyroid carcinoma and mutation analysis of CTNNB1 and BRAF genes. Thyroid 19 905-913. (doi:10.1089/thy.2008.0332)

Kameyama K \& Takami H 2001 FAP associated thyroid carcinoma in mother and her daughter. Familial Cancer 1 83-86. (doi:10.1023/A:1013848307459)

Kameyama K, Mukai M, Takami H \& Ito K 2004 Cribriform-morular variant of papillary thyroid carcinoma: ultrastructural study and somatic/germline mutation analysis of the APC gene. Ultrastructural Pathology 28 97-102. (doi:10.1080/01913120490431435)

Klugbauer S, Lengfelder E, Demidchik EP \& Rabes HM 1995 High prevalence of RET rearrangement in thyroid tumors of children from Belarus after the Chernobyl reactor accident. Oncogene $\mathbf{1 1}$ 2459-2467.

Koo JS, Jung W \& Hong SW 2011 Cytologic characteristics and $\beta$-catenin immunocytochemistry on smear slide of cribriform-morular variant of papillary thyroid carcinoma. Acta Cytologica 55 13-18. (doi:10.1159/000320856)

Kuma S, Hirokawa M, Xu B, Miyauchi A, Kukudo K \& Sano T 2004 Cribriform-morular variant of papillary thyroid carcinoma. Report of a case showing morules with peculiar nuclear clearing. Acta Cytologica 48 431-436. (doi:10.1159/000326399)

Kwon MJ, Rho YS, Jeong JC, Shin HS, Lee JS, Cho SJ \& Nam ES 2015 Cribriform-morular variant of papillary thyroid carcinoma: a study of 3 cases featuring the PIK3CA mutation. Human Pathology 46 1180-1188. (doi:10.1016/j.humpath.2015.04.010)

Lam AK 2017 Pathology of endocrine tumors update: WHO new classification 2017 - other thyroid tumors. AJSP: Reviews and Reports [in press].

Lam AK \& Lo CY 2006 Diffuse sclerosing variant of papillary carcinoma of the thyroid: a 35-year comparative study at a single institution. Annuals of Surgical Oncology 13 176-181. (doi:10.1245/ ASO.2006.03.062)

Lam KY, Montone KT, Nolan KA \& LiVolsi VA 1998 Ret oncogene activation in papillary thyroid carcinoma: Prevalence and implication on the histological parameters. Human Pathology 29 565-568. (doi:10.1016/S0046-8177(98)80004-X)

Lam AK, Lo CY \& Lam KS 2005 Papillary carcinoma of thyroid: a 30-year clinicopathological review of the histological variants. Endocrine Pathology 16 323-330. (doi:10.1385/EP:16:4:323)

Lam AK, Carmichael R, Gertraud Buettner P, Gopalan V, Ho YH \& Siu S 2011 Clinicopathological significance of synchronous carcinoma in colorectal cancer. American Journal of Surgery 202 39-44. (doi:10.1016/j.amjsurg.2010.05.012)

Lam AK, Chan SS \& Leung M 2014 Synchronous colorectal cancer: clinical, pathological and molecular implications. World Journal of Gastroenterology 20 6815-6820. (doi:10.3748/wjg.v20.i22.6815)

Leoz ML, Carballal S, Moreira L, Ocaña T \& Balaguer F 2015 The genetic basis of familial adenomatous polyposis and its implications for clinical practice and risk management. Application of Clinical Genetics 8 95-107. (doi:10.2147/TACG.S51484)

Levy RA, Hui VW, Sood R, Fish S, Markowitz AJ, Wong RJ \& Guillem JG 2014 Cribriform-morular variant of papillary thyroid carcinoma: an indication to screen for occult FAP. Familial Cancer 13 547-551. (doi:10.1007/s10689-014-9732-5)

Liyanapathirana N, Seneviratne SA \& Samarasekera DN 2015 A distinct variant of papillary thyroid carcinoma indicating familial adenomatous polyposis (FAP): a case report and brief review. BMC Research Notes 8 795. (doi:10.1186/s13104-015-1736-1)

Lo CY, Lam KY, Chan KT \& Luk JM 1999 Telomerase activity in thyroid malignancy. Thyroid 9 1215-1220. (doi:10.1089/thy.1999.9.1215)

Melo M, da Rocha AG, Vinagre J, Batista R, Peixoto J, Tavares C, Celestino R, Almeida A, Salgado C, Eloy C, et al. 2014 TERT http://erc.endocrinology-journals.org

DOI: 10.1530/ERC-17-0014
๑ 2017 Society for Endocrinology Printed in Great Britain
Published by Bioscientifica Ltd 
promoter mutations are a major indicator of poor outcome in differentiated thyroid carcinomas. Journal of Clinical Endocrinology and Metabolism 99 E754-E765. (doi:10.1210/jc.2013-3734)

Mizukami Y, Nonomura A, Michigishi T, Noguchi M \& Ishizaki T 1996 Encapsulated follicular thyroid carcinoma exhibiting glandular and spindle cell components: a case report. Pathology Research Practice 192 67-71. (doi:10.1016/S0344-0338(96)80134-8)

Mogoş V, Mogoş S, Sfarti C, Băcăuanu R, Huţanu O, Cotea E, Ciobanu D, Tudorache C \& Târcoveanu E 2012 Familial syndromic papillary thyroid carcinoma report of two cases. Revista Medico-Chirurgicala A Societatii de Medici si Naturalisti din Iasi 116 1048-1054.

Nakazawa T, Celestino R, Machado JC, Cameselle-Teijeiro JM, Vinagre J, Eloy C, Benserai F, Lameche S, Soares P \& SobrinhoSimões M 2013 Cribriform-morular variant of papillary thyroid carcinoma displaying poorly differentiated features. International Journal of Surgical Pathology 21 379-389. (doi:10.1177/1066896912473355)

Ng SB, Sittampalam K, Goh YH \& Eu KW 2003 Cribriform-morular variant of papillary carcinoma: the sporadic counterpart of familial adenomatous polyposis-associated thyroid carcinoma: a case report with clinical and molecular genetic correlation. Pathology 35 42-46. (doi:10.1080/00313020307507)

Nikiforov YE 2002 RET/PTC rearrangement in thyroid tumors. Endocrine Pathology 13 3-16. (doi:10.1385/EP:13:1:03)

Oh EJ, Lee S, Bae JS, Kim Y, Jeon S \& Jung CK 2016 TERT promoter mutation in an aggressive cribriform morular variant of papillary thyroid carcinoma. Endocrine Pathology 28 49-53. (doi:10.1007/ s12022-016-9454-3)

Pacini F \& Castagna MG 2012 Approach to and treatment of differentiated thyroid carcinoma. Medical Clinics North America 96 369-383. (doi:10.1016/j.mcna.2012.01.002)

Pakneshan S, Salajegheh A, Smith RA \& Lam AK 2013 Clinicopathological relevance of BRAF mutations in human cancer. Pathology 45 346-356. (doi:10.1097/PAT.0b013e328360b61d)

Perea Del Pozo E, Ramirez Plaza C, Padillo Ruiz J \& Martos Martínez JM 2015 Cribiform variant of papillary thyroid cancer and familial adenomatous polyposis. International Journal of Surgery Case Reports 16 192-194. (doi:10.1016/j.ijscr.2015.08.013)

Perrier ND, van Heerden JA, Goellner JR, Williams ED, Gharib H, Marchesa P, Church JM, Fazio VW \& Larson DR 1998 Thyroid cancer in patients with familial adenomatous polyposis. World Journal of Surgery 22 738-742. (doi:10.1007/s002689900462)

Pillai S, Gopalan V, Smith RA \& Lam AK 2015 Diffuse sclerosing variant of papillary thyroid carcinoma-an update of its clinicopathological features and molecular biology. Critical Reviews in Oncology Hematology 94 64-73. (doi:10.1016/j.critrevonc.2014.12.001)

Rahman MA, Salajegheh A, Smith RA \& Lam AK 2015 Multiple proliferation-survival signalling pathways are simultaneously active in BRAF V600E mutated thyroid carcinomas. Experimental and Molecular Pathology 90 492-497. (doi:10.1016/j. yexmp.2015.09.006)

Rahman MA, Salajegheh A, Smith RA \& Lam AK 2016 Inhibition of BRAF kinase suppresses cellular proliferation, but not enough for complete growth arrest in BRAF V600E mutated papillary and undifferentiated thyroid carcinomas. Endocrine 54 129-138. (doi:10.1007/s12020-016-0985-7)

Raue F \& Frank-Raue K 2016 Thyroid cancer: risk-stratified management and individualized therapy. Clinical Cancer Research 22 5012-5021. (doi:10.1158/1078-0432.CCR-16-0484)

Reguart N, He B, Taron M, You L, Jablons DM \& Rosell R 2005 The role of Wnt signaling in cancer and stem cells. Future Oncology $\mathbf{1}$ 787-797. (doi:10.2217/14796694.1.6.787)

Rocha AS, Soares P, Seruca R, Máximo V, Matias-Guiu X, CameselleTeijeiro J \& Sobrinho-Simões M 2001 Abnormalities of the E-cadherin/catenin adhesion complex in classical papillary thyroid carcinoma and in its diffuse sclerosing variant. Journal of Pathology 194 358-366. (doi:10.1002/path.905)

Rohaizak M, Jasmi AY, Ismail MA, Munchar MJ \& Meah FA 2003 Thyroid carcinoma in patients with familial adenomatous polyposis. Asian Journal of Surgery 26 183-185. (doi:10.1016/S10159584(09)60381-X)

Rosen EJ, Newlands SD \& Rampy BA 2003 Pathology quiz case: cribriform-morular variant of papillary thyroid carcinoma. Archives of Otolaryngology - Head and Neck Surgery 129 679-681. (doi:10.1001/ archotol.129.6.679)

Rossi ED, Revelli L, Martini M, Taddei A, Pintus C, Panunzi C \& Fadda G 2012 Cribriform-morular variant of papillary thyroid carcinoma in an 8-year-old girl: a case report with immunohistochemical and molecular testing. International Journal of Surgical Pathology 20 629-632. (doi:10.1177/1066896912441830)

Schaeffer DF, Yoshida EM, Owen DA \& Berean KW 2011 Familial adenomatous polyposis-rendering a diagnosis based on recognition of an unusual primary thyroid neoplasm. Case Report in Medicine 2011 article ID 767610. (doi:10.1155/2011/767610)

Si HX, Tsao SW, Lam KY, Srivastava G, Liu Y, Wong YC, Shen ZY \& Cheung ALM 2001 E-cadherin expression is commonly downregulated by CpG island hypermethylation in esophageal carcinoma cells. Cancer Letters 173 71-78. (doi:10.1016/S03043835(01)00646-2)

Skomorowski M, Taxier M \& Wise W Jr 2012 Turcot syndrome type 2: medulloblastoma with multiple colorectal adenomas. Clinical Gastroenterology and Hepatology 10 A24. (doi:10.1016/j. cgh.2012.06.013)

Smith RA, Salajegheh A, Weinstein S, Nassiri M \& Lam AK 2011 Correlation between BRAF mutation and the clinicopathological parameters in papillary thyroid carcinoma with particular reference to follicular variant. Human Pathology 42 500-506. (doi:10.1016/j. humpath.2009.09.023)

Soravia C, Sugg SL, Berk T, Mitri A, Cheng H, Gallinger S, Cohen Z, Asa SL \& Bapat BV 1999 Familial adenomatous polyposis-associated thyroid cancer: a clinical, pathological, and molecular genetics study. American Journal of Pathology 154 127-135. (doi:10.1016/ S0002-9440(10)65259-5)

Subramaniam MM, Putti TC, Anuar D, Chong PY, Shah N, SaltoTellez M \& Soong R 2007 Clonal characterization of sporadic cribriform-morular variant of papillary thyroid carcinoma by laser microdissection-based APC mutation analysis. American Journal of Clinical Pathology 128 994-1001. (doi:10.1309/ YXR3PKK4TV3DJC56)

Tomoda C, Miyauchi A, Uruno T, Takamura Y, Ito Y, Miya A, Kobayashi K, Matsuzuka F, Kuma S, Kuma K, et al. 2004 Cribriformmorular variant of papillary thyroid carcinoma: clue to early detection of familial adenomatous polyposis-associated colon cancer. World Journal of Surgery 28 886-889. (doi:10.1007/s00268004-7475-4)

Uchino S, Noguchi S, Yamashita H, Yamashita H, Watanabe S, Ogawa T, Tsuno A, Murakami A \& Miyauchi A 2006 Mutational analysis of the APC gene in cribriform-morula variant of papillary thyroid carcinoma. World Journal of Surgery 30 775-779. (doi:10.1007/s00268005-0368-3)

Vinagre J, Almeida A, Pópulo H, Batista R, Lyra J, Pinto V, Coelho R, Celestino R, Prazeres H, Lima L, et al. 2013 Frequency of TERT promoter mutations in human cancers. Nature Communications $\mathbf{4}$ 2185. (doi:10.1038/ncomms3185)

Waller A, Findeis S \& Lee MJ 2016 Familial adenomatous polyposis. Journal of Pediatric Genetics 5 78-83. (doi:10.1055/s-0036-1579760)

Xing M, Alzahrani AS, Carson KA, Viola D, Elisei R, Bendlova B, Yip L, Mian C, Vianello F, Tuttle RM, et al. 2013 Association between BRAF V600 mutation and mortality in patients with papillary thyroid cancer. JAMA 309 1493-1501. (doi:10.1001/jama.2013.3190)
() 2017 Society for Endocrinology Printed in Great Britain
Published by Bioscientifica Ltd. 
Xing M, Alzahrani AS, Carson KA, Shong YK, Kim TY, Viola D, Elisei R, Bendlová B, Yip L, Mian C, et al. 2015 Association between BRAF V600E mutation and recurrence of papillary thyroid cancer. Journal of Clinical Oncology 33 42-50. (doi:10.1200/JCO.2014.56.8253)

Xu B, Yoshimoto K, Miyauchi A, Kuma S, Mizusawa N, Hirokawa M \& Sano T 2003 Cribriform-morular variant of papillary thyroid carcinoma: a pathological and molecular genetic study with evidence of frequent somatic mutations in exon 3 of the betacatenin gene. Journal of Pathology 199 58-67. (doi:10.1002/ path.1225)

Yamashita T, Hosoda Y, Kameyama K, Aiba M, Ito K \& Fujimoto Y 1992 Peculiar nuclear clearing composed of microfilaments in papillary carcinoma of the thyroid. Cancer $702923-2928$. (doi:10.1002/1097-0142(19921215)70:12<2923::AIDCNCR2820701232>3.0.CO;2-G)

Yeoh EC, Lim LC, Ng SB, Tan KY \& Rajasoorya C 2014 Cribriform morular variant of papillary thyroid carcinoma in a patient with an incidental neck lump: a case report and review of the literature. Endocrine Pathology 25 302-306. (doi:10.1007/s12022-013-9274-7)

Yoo SK, Lee S, Kim SJ, Jee HG, Kim BA, Cho H, Song YS, Cho SW, Won JK, Shin JY, et al. 2016 Comprehensive analysis of the transcriptional and mutational landscape of follicular and papillary thyroid cancers. PLoS Genetics 12 e1006239. (doi:10.1371/journal. pgen.1006239)

Received in final form 7 February 2017

Accepted 13 February 2017
Published by Bioscientifica Ltd. 